\title{
Teachers' Attitude towards English in Batu Anam
}

\author{
Mah Zhi Jian and Lee Poh Lin \\ (University of Malaya, Malaysia) \\ doi:10.7575/aiac.alls.v.2n.2p.232
}

\section{Abstract}

This research investigates the attitude of 60 primary and secondary school teachers towards English in Batu Anam. A questionnaire was administered to find out whether they have a positive or a negative attitude towards the English language. Results indicate that teachers in Batu Anam generally have a positive attitude towards English. Comparison between male and female teachers, optionist and non-optionist teachers and teachers from different types of schools are also analyzed.

\section{Introduction}

With increasing attention being given to teaching English in primary and secondary schools, it seems appropriate that English educators should become concerned with teachers' attitudes towards the English language in the classrooms.

Realising the importance of English as a language of dissemination of ideas and knowledge, a survey was conducted to determine the teachers' attitude towards English in Batu Anam, Johor. Batu Anam is a small town in the Segamat District in Johor, a southern state in Malaysia.

\section{Research problem}

Currently, there is a lack of research on the attitude of teachers towards English in Malaysia. The need to determine the attitude is even more pressing because some of the teachers who teach English in Malaysia are not English language optionists. It is likely that these teachers may not have positive attitudes towards the English language. In fact negative attitudes towards English can have a negative impact on one's teaching practice as well as students' achievement. 
In the state of Johor, approximately 2956 out of 4371 (67.63\%) of English language teachers are non-optionist (personal communication with Johor State Education Department officer, August 22, 2009). Furthermore, the performance of the students for the English language is still not at its best level. In the year 2008, less than 5000 students managed to score straight A's from a total of 55,714 students who sat for their Ujian Penilaian Sekolah Rendah (UPSR) National examination. According to the Johor Director of Education, Tuan Haji Sufaat bin Tumin (personal communication), 4,058 students scored 5As in their UPSR while 1,343 scored B in one subject which is English. The number of straight A students would increase to 5,401 if the 1,343 students scored A in English. Hence, the Johor State Education Department has identified the results of the English language paper as the main cause for its weak performance in the UPSR exam.

Therefore the question we should be asking right now is: Could the performance of the students be an indicator that the English language teachers are not performing at their optimal and could this in turn be due to the attitude of teachers themselves towards English? These issues can be explored if a study is conducted on the attitude to investigate the attitudes of teachers towards English.

\section{Conceptual framework}

The cycle of the relationship between attitudes and teaching practices can be summarised as follows (Smith, 1993):

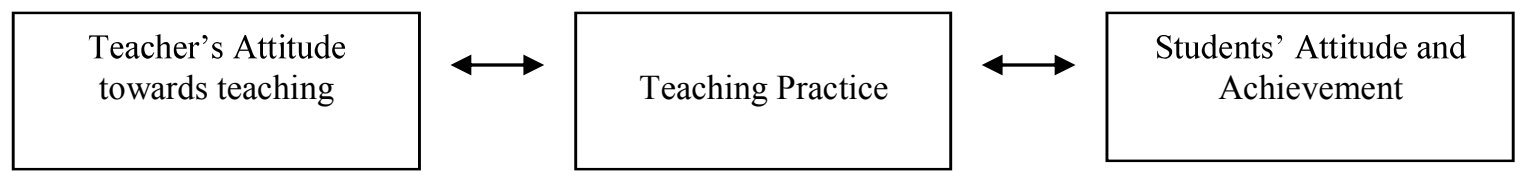

Figure 1: The cycle of the relationship between attitudes and teaching practices

This study, as stated earlier, addresses primary and secondary school teachers' attitude towards English Language in the classroom. It attempts to explore teachers' attitude in relation to the language. In addition, the study is limited to find out the possible constraints teachers face in teaching English. To keep the study in a manageable size, we have randomly selected 60 English teachers around the schools in Batu Anam. 


\section{Objective of study}

This study aims to survey the attitudes of teachers teaching in schools around the Batu Anam, Segamat area towards the English language.

\section{Research question}

1) What is the attitude towards English among teachers in Batu Anam?

2) Are there any significant differences in the attitude towards English among teachers in Batu Anam with respect to:
a) Gender
b) Option (Major during teacher training)
c) Type of schools

\section{Significance of the study}

Gunderson (2004) asserted that people's attitude towards their professions have an effect on their performance. This case is also valid for the teaching profession. The attitude of teachers towards English is important if they are to play a significant role in shaping their students' achievements. Hence this research is important because there is a need to determine the attitude of teachers towards English.

The results obtained from this research will be a useful guide to the teachers and future teachers in improving their attitude towards English. This study aims to sufficiently equip teachers and prepare learners to become empowered communicators of English.

Positive attitudes shown by the teachers will have a better impact on students' attitudes and performance levels. However, if most teachers are skeptical and show negative attitudes towards English, it could have a negative impact on the teachers' teaching practice subsequently contributing to the declineof the English result in the school as well as in the district and state. Steps can be formulated to help boost teachers' negative attitudes to have a better and more productive outlook in teaching English. Whereas for the students, positive teacher attitudes may produce sound achievements while negative attitudes may in general affect students' results. It is hoped that the study will benefit both the teachers and students respectively in teaching and learning English in the classroom. 


\section{Literature review}

\section{Definition of attitude}

Fishman (1976) defined attitude as within the framework of social psychology as a subjective or mental preparation for action. Attitude defines the outward and visible postures and human beliefs - the individual's prevailing tendency to respond favourably or unfavourably to an object (person or group of people, institutions or events).

Agheyisi and Fishman (1976) suggested that attitude is a mental and neural state of readiness exerting a direct influence upon the individual's response to all objects and situations with which it is related. Krech and Crutchfield (1948) described attitude as an enduring organization of motivational, emotional, perceptual and cognitive processes with respect to some aspect of individual's world. While Doob (1954) looked at the term as an implicit response that is both anticipatory and mediating in reference to patterns of overt responses that is considered socially significant in individual's world, Green (1954) suggested the consistency or co-variation of a number of different responses to stimuli of the same general class as a definition for attitude.

\section{Components of attitude}

Osgood (1954) believed that attitude has a unitary structure and it cannot be divided. These components are:

1. cognitive: the believes one has about an attitude object.

2. affective: the feelings attached to an attitude object.

3. behavioral: the behavioral readiness of the individual to respond to the object.

\section{Attitude and motivation}

Gardner and Lambert (1972) explored the relationship between attitude and motivation. They compared the attitudes of 170 French learners with their final exam achievements and concluded that positive orientation toward learning French has a significant impact on successful learning. They reported that attitude plays a crucial role in second language acquisition.

\section{Studies in Malaysian context}

There are several studies in the context of Malaysia exploring the attitudes and its relation with other human constructs like motivation. Charanjit (1998) explored the attitudes of undergraduates towards English in two faculties at the Universiti of Malaya. The study 
showed that the undergraduates in both faculties have positive attitudes towards the social and instrumental value of English. Another study conducted by Chow (2001) investigated the attitudes of Malay and Chinese undergraduates towards English and concluded that the attitudes towards the socialistic values of English is positive among the undergraduates.

There are a few studies concerning the teachers' attitudes toward English. Chuansit (1983) assessed the teachers' attitudes towards the teaching of English in Thailand. The result of this study indicates that teachers' positive attitudes towards the teaching of English have a positive impact on their teaching practice.

From the aforementioned researches, much work has been done on the learners' attitudes towards English and language learning but very few studies deal with the teachers' attitudes towards English. Those researches probing this issue generally study the teachers' attitudes towards the teaching of English, English varieties and linguistic approaches, but not English per se. As the importance of attitudes in educational and social studies has been proven, this study aims to investigate the teachers' attitudes toward English to fill the gap in this area.

\section{Methodology}

The main aim of this research is to test attitudes of the teachers of Batu Anam towards English. Information about the participants of the research, the instrument used in this research, data collection and analysis procedures will be presented..

\section{Participants}

The participants of the research consisted of 60 respondents (21 males and 39 females) which were randomly selected from both Primary, including National schools (SK) and Nationaltype schools (SJK) and Secondary schools in the area.

\section{Instrument}

The instrument used for this research is a questionnaire (refer to Appendix A) which consists of twenty-two direct attitude questions. The questionnaire was adapted from Pennington and Yue's study (1994) in Hong Kong. The adapted questionnaire was modified to suit the Malaysian context. Participants were asked to rate statements based on their attitudes towards English and its use in education and social interaction. The answer choice is provided by a 
Likert scale ranging from" absolutely agree" to" absolutely disagree". There were four alternatives available as follows:

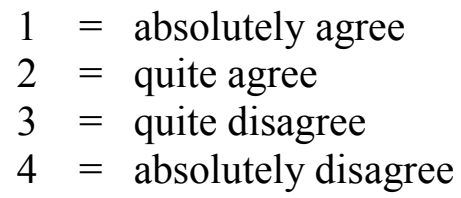

The respondents were asked to answer each of the statements in the questionnaire by circling one of the four numbers 12234 . A "no option" answer choice was eliminated because "inclusion of a neutral midpoint tends to encourage a neutral or superficial response and enhances central tendency" (Pennington and Yue, 1994, p.7).

\section{Format of the questionnaire}

The questionnaire consists of two sections:

\section{Section A}

The background information of participants such as gender, school, medium of instruction during secondary and tertiary level of education, major during teacher training, the use of English outside of classroom, experience in teaching English and the highest level of education is elicited in this section.

\section{Section B}

This section is composed of twenty-two statements about the respondents' attitude towards English. Positive and negative attitudes towards English are shown in some of the statements.

Examples of statements which demonstrate positive attitudes towards English are:

7. To read English magazines is a kind of enjoyment.

9. I love conversing with foreigners in English.

18. The English language sounds very nice.

11. I like to watch English-speaking films.

Examples of statements which represent negative attitudes towards English are:

20. I feel uneasy when hearing a Malaysian speaking English.

16. I feel uneasy and lack of confidence when speaking English. 
14. I feel uncomfortable when hearing a Malaysian speaking to another Malaysian of the same race in English.

\section{Data collection}

The questionnaire was administered to the teachers in schools in the Batu Anam area from $17^{\text {th }}$ August 2009 to $20^{\text {th }}$ August 2009. The teachers were asked to give honest answers to the questionnaire.

\section{Procedure of data analysis}

The questionnaires were collected and the scores were calculated to find the mean. One way analysis and $t$-test analysis were also done to determine the significance of the finding. The data was analysed using the SPSS version 11.5.

\section{Scoring}

First, each item on the questionnaire was given a score. The scoring method is as below:

The direct attitude questionnaire is composed of 22 Likert statements demanding respondents to point out whether they "absolutely agree", "quite agree", "quite disagree" and "absolutely disagree" with them. Each item was allotted scores between 1 and 4.

$$
\begin{aligned}
& 1=\text { absolutely agree } \\
& 2=\text { quite agree } \\
& 3=\text { quite disagree } \\
& 4=\text { absolutely disagree }
\end{aligned}
$$

As items 3, 5, 10, 12, 14, 16, 20 and 21 were negatively phrased, the scoring reversed, 1 for 'absolutely disagree' and 4 for 'absolutely agree'

The group mean was computed. If the group mean is below 2.5 , it means the participants have positive attitude towards English and a group mean of 2.5 and above denotes negative attitudes.

Table 1.0 Criteria to determine positive or negative attitude

\begin{tabular}{ll}
\hline Mean & Description \\
\hline Below 2.5 & Positive attitude towards English \\
2.5 and above & Negative attitude towards English \\
\hline
\end{tabular}


In $t$-test analysis, statistical significance of $\mathrm{P}<0.05$ level was computed, with all $p$-values being reported as two-tailed tests.

\section{Findings of the study}

The results of the analysis of quantitative data in this study and the interpretations made based on them are organized into two parts:

(a) Descriptive statistics of teachers' attitude towards English for the sample as a whole.

(b) Descriptive statistics of teachers' attitude towards English according to gender, option and type of schools.

\section{Descriptive statistics of teachers' attitude for the whole sample}

As shown in Table 2.1, for the sample as a whole, the mean score for teachers' attitude towards English was 2.27 while the standard deviation was 0.50 . The median was 2.18 and the range was from a minimum of 1.18 to a maximum of 3.55 . Based on the results and on table 3.2, the teachers in Batu Anam generally have a positive attitude towards English. As discussed in section 2.1, this means that they value the English language and tend to respond favorably to it.

Table 2.1: Descriptive statistics of teachers' attitude towards English in Batu Anam

\begin{tabular}{ll} 
Mean & 2.27 \\
Median & 2.18 \\
Minimum & 1.18 \\
Maximum & 3.55 \\
Standard Deviation & 0.50 \\
\hline
\end{tabular}

Descriptive statistics of teachers' attitude towards English according to gender, option and type of schools

Table 2.2 shows the descriptive statistics for the teachers' attitude towards English according to the independent variables, which are gender, option and types of school. From Table 2.2, male teachers scored a mean of 2.36 and female teachers scored 2.28. The mean for optionist was 1.98 and 2.33 for non-optionist. The mean difference was 0.35 . For the different types of school, teachers from SK scored the highest mean, which was 2.13 while the lowest mean was 2.64 for teachers from SJK (T) for the sample. 
Table 2.2: Mean and standard deviation of attitude towards English according to the independent variables for the sample on their attitudes towards English

\begin{tabular}{lcccccccc}
\hline & \multicolumn{2}{c}{ Gender } & \multicolumn{2}{c}{ Option } & \multicolumn{3}{c}{ Type of schools } \\
& Male & Female & Optionist & Non-optionist & SK & SJK(C) & SJK(T) & SMK \\
\hline Mean & 2.36 & 2.28 & 1.98 & 2.33 & 2.13 & 2.25 & 2.64 & 2.16 \\
StandardDeviation & 0.67 & 0.38 & 0.42 & 0.50 & 0.24 & 0.46 & 0.80 & 0.34 \\
\hline
\end{tabular}

Comparison of Batu Anam teachers' attitude towards English between male and female teachers

Table 2.3 shows the results of $t$-test analysis between male and female teachers' attitude towards English. From Table 2.3, female teachers have a mean of 2.22 while the male teachers have a mean of 2.36. The results show that female teachers have a lower mean than the male teachers. However, $t$-test analysis shows that the difference was not significant, $t(58)=1.07, p=0.29$. The results indicate that there is no difference in attitude towards English between male and female teachers.

Table 2.3: Comparison of attitudes towards English between male and female teachers in Batu Anam

\begin{tabular}{lllll}
\hline & Mean & Standard Deviation & $\boldsymbol{t}$-value & $\boldsymbol{p}$-value \\
\hline Male & 2.36 & 0.67 & 1.068 & 0.290 \\
Female & 2.22 & 0.38 & & \\
\hline
\end{tabular}

Comparison of Batu Anam teachers' attitude towards English between optionist and nonoptionist teachers

Table 2.4 shows the results of $t$-test analysis between optionists and non-optionists with regard to their attitude towards English. From Table 2.4, the optionists obtained a mean of 1.98 while the non-optionists obtained a mean of 2.33. The mean difference was 0.35 . Results of $t$-test analysis show the difference to be significant, $t(58)=-2.05, p=0.045$. The results indicate that optionist and non-optionist teachers differ significantly in their attitude towards English based on the criteria in Table 1.0. Teachers whose major was English during teachers training, or known as English optionist, have a more positive attitude towards English.

Table 2.4: Comparison of optionist and non-optionist teachers' attitude towards English in Batu Anam

\begin{tabular}{lllll}
\hline & Mean & Standard Deviation & $t$-value & $p$-value \\
Optionists & 1.98 & 0.42 & -2.05 & $0.045^{*}$ \\
Non-optionists & 2.33 & 0.50 & & \\
\hline * significant at $p<0.05$ & &
\end{tabular}


Comparison of teachers' attitude towards English according to the type of schools

The means and standard deviations of teachers' attitude from the different type of schools are provided in table 2.5. The results of the one-way analysis of variance for the type of schools are provided in Table 2.6. Table 2.7 shows the results of the Tukey HSD post-hoc multiple comparisons.

From Table 2.5, SK, SJK (C), SJK (T) and SMK obtained means of 2.13, 2.25, 2.64 and 2.16 respectively. The results of the one-way analysis of variance, as shown in Table 2.6, shows a significant difference in the means, $F(3,56)=2.96, M S E=0.23, p=0.04$. Post-hoc multiple comparisons using the Tukey HSD tests indicated significant differences between the SJK (T) and SMK, $M D=0.48, p=0.04$. This indicates teachers in SMK have a more positive attitude towards English as compared to teachers from SJK (T).

Table 2.5: Means and Standard Deviations of teachers' attitude to the type of schools

\begin{tabular}{lll}
\hline Type of schools & Mean & Standard Deviation \\
\hline SK & 2.13 & 0.24 \\
SJK (C) & 2.25 & 0.46 \\
SJK (T) & 2.64 & 0.80 \\
SMK & 2.16 & 0.34 \\
\hline
\end{tabular}

Table 2.6: One way analysis of variance on the type of schools on teachers' attitude towards English

\begin{tabular}{lllllll}
\hline Dependent Variable & Source & Sum of Squares & Df & Mean Square & $F$ & $p$ \\
\hline Types of schools & Between gps & 1.999 & 3 & 0.67 & 2.964 & 0.04 \\
& Within gps & 12.587 & 56 & 0.23 & & \\
& Total & 14.586 & 59 & & & \\
\hline
\end{tabular}

Table 2.7: Tukey post-hoc comparisons on the dependent variables for the sample on teachers' attitude towards English

\begin{tabular}{llllc}
\hline Dependent Variable & (I) SCHOOL & (J)SCHOOL & Mean difference $(M D)(\mathrm{I}-J)$ & $p$ \\
\hline Types of schools & SK & SJK (C) & -0.13 & 0.91 \\
& & SJK (T) & -0.51 & 0.08 \\
& & SMK & -0.03 & 1.00 \\
\hline & SJK (C) & SK & 0.13 & 0.91 \\
& & SJK (T) & -0.39 & 0.16 \\
& & SMK & 0.10 & 0.92 \\
\hline & SJK(T) & SK & 0.51 & 0.08 \\
& & SJK(C) & 0.39 & 0.16 \\
& SMK & 0.48 & 0.04 \\
\hline & SMK & SK & 0.03 & 1.00 \\
& & SJK (C) & -0.97 & 0.92 \\
& & SJK (T) & -0.48 & 0.04 \\
\hline
\end{tabular}




\section{Discussion and conclusion}

Results from the questionnaire show that the English teachers in Batu Anam have positive attitudes towards English. Although the sample does not represent the whole population, it is still a very encouraging result for the education system as it indicates that the teachers value the language. Perhaps more research on teachers' attitude could be conducted as teachers' beliefs and attitude towards English will influence their teaching.

Based on the findings too, we discover that the mean for optionist is 1.98 and 2.33 for nonoptionist. This may indicate that the amount of formal training a teacher receives in teacher training colleges can affect his or her attitude. Therefore, English teachers should be given training to develop themselves professionally. In relation to these outcomes, it is strongly recommended that teachers who are non-optionists have more opportunities to work with teachers who are optionists to make themselves better English teachers.

The results also highlight that the female teachers have a lower mean than the mean of the male teachers in terms of their scores in attitude. However, $t$-test analysis indicates that there is no significant difference in the attitude between the female and male teachers. A nationwide survey could be carried out to determine whether gender affects one's attitude towards English.

Another outcome of the study indicates that the teachers in SMK have more positive attitude as compared to the teachers in $\mathrm{SJK}(\mathrm{T})$. This implies that the teachers in SJK (T) may need further training and motivation to help them cope with the language as well as to increase their awareness of the importance of having the right attitude towards the language.

For future research, in line with the government's recent emphasis on English, a follow up study to determine teachers' attitude towards English in Malaysia on a larger scale should be conducted to investigate the general attitude of these teachers towards the language. Further studies will help teachers in this nation to have optimistic attitudes towards English and realise the importance of teaching and learning this language in order to be fluent users and produce students who are proficient in the language.

From the review of literature, most studies deal with learners' attitude towards the English language and how it has affected their language learning. Not much has been said about 
teachers' attitude towards the English language. Chuansit's (1983) study reported that teachers' attitude has an impact on the practice of teaching English in Thailand. This research, however, has not looked into how teachers' attitude towards English influences their practice in English language teaching. A further research could be carried out to find out whether there is a correlation between having a positive attitude towards English and good teaching practice of teachers in Malaysia.

\section{References}

Aghevisi, R. \& Fishman, J.A. (1976). A Consideration of beliefs, attitudes and their relationships. In Steiner and M. Fishbein (Eds.) Current studies in social psychology.107-20 New York: Holt, Rinehart \& Winston.

Charanjit, S.D. (1998). Attitudes of undergraduates towards English in two faculties at Universiti Malaya. Unpublished M.A. Dissertation. Universiti Malaya.

Chow, S.L. (2001). Attitudes of Malay and Chinese Undergraduates towards English.Unpublished M.A Dissertation. Universiti Malaya

Chuansnit, S. (1983). An assessment of teacher attitudes toward the teaching of English in Thailand.Unpublished M.A dissertation. Universiti Malaya.

Doob (1954). The Behavior of Attitudes. In K. Thomas (Ed.) Attitudes and Behavior: Selected readings. Middlesex: Penguin.

Fishman, J.A. (1976). Bilingual Education: An Introductional Sociological Perspective. Rowley Mass: Newbury House.

Gardner, R.G. \& Lambert, W.E. (1972). Attitudes and Motivation in Second language Learning. Newbury: Newbury House Publishers.

Green, B. F. (1954). Attitude measurement. MA: Addison-Weasley.

Gunderson, A. (2004). For the Love of Kids. NEA Today, Vol.22. (5), p.64.

Jabatan Pelajaran Negeri Johor. Retrieved August 24, 2008 from http://www.moe.gov.my/jpnjohor/v3/johor.php?bhs=bm

Krech, D. \& Crutchfeil, R.S (1948). Theory and Problems of Psychology. New York: McGraw Hill.

Osgood, C.E. (1954). Attitude Change: The Competing Views. MA: Addison-Weasley.

Pennington, M.C. \& Yue, F. (1994). English and Chinese in Hong Kong. Pre-1997 language attitudes. World Englishes, 13, 1-20.

Smith, D.M. (1993). Pre-service Elementary Teachers' Attitude Towards The Teaching of English in the Constructivist Classroom. McGraw Hill: New York.

Tuan Haji Sufaat bin Tumin (2009). Tumin, Johor Director of Education, stated in a personal email on $30^{\text {th }}$ August. 


\section{Appendix A: Direct attitude questionnaire}

Please answer the following questions by putting a tick $(\sqrt{ })$ in the appropriate box.

\section{SECTION A}

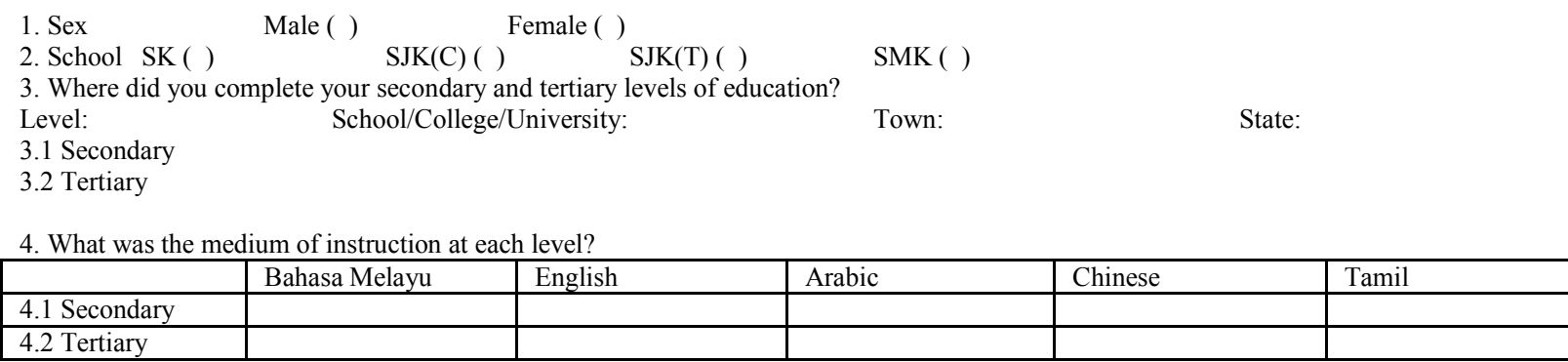

5. Have you ever had any professional English training to teach English?

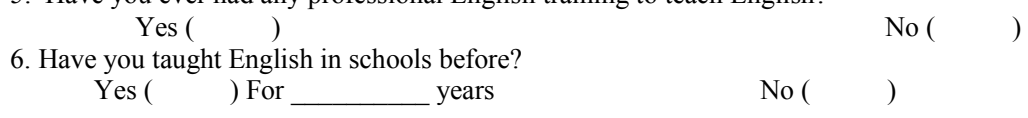

7. How often do you use English outside the classroom? Please tick.

\begin{tabular}{|l|l|l|l|l|l|}
\hline & Very Often & Often & Sometimes & Seldom & Never \\
\hline while interacting with your friends & & & & & \\
\hline while reading reference materials & & & & & \\
\hline
\end{tabular}

8. Is your major in English during your teacher training?

Yes ( No ( ) Please state:

9. What is your highest level of education?

$\begin{array}{lll}\text { SPM }(\quad) & \operatorname{STPM}(\quad) & \text { Diploma ( ) } \\ \text { Bachelor Degree }(\quad) & \text { Masters ( ) }\end{array}$

\section{SECTION B}

Do you agree with the following statements?

Circle ONE of the four numbers:

$1=$ absolutely agree $\quad 2$ = quite agree $\quad 3=$ quite disagree $\quad 4=$ absolutely disagree

Statement

It is a good thing to have English as a compulsory second language in Malaysian schools.

English is the mark of an educated person.

When using English, I do not feel that I am Malay/Chinese/Indian anymore.

If I use English, I will be praised and approved of by my family, relatives and friends.

At times I fear that by using English I will become like a foreigner.

I should not be forced to learn English.

To read English magazines is a kind of enjoyment.

I do not feel awkward when using English.

I love conversing with foreigners in English.

0 My mother tongue is more important than English.

I like to watch English-speaking films.

If I use English, it means that I am not patriotic.

If I use English, my status is raised.

I feel uncomfortable when hearing a Malaysian speaking to another Malaysian of the same race in English.

I wish I could speak fluent and accurate English.

I feel uneasy and lack of confidence when speaking English.

$\begin{array}{llll}1 & 2 & 3 & 4\end{array}$ prosperity and development today.

18 The English language sounds very nice.

19 I would take English even if it were not a compulsory subject in school.

20 I feel uneasy when hearing a Malaysian speaking English

21 English should not be a medium of instruction for Science and Mathematics in Malaysian schools.

22 The command of English is very helpful in understanding foreigners and their cultures.

$\begin{array}{llll}1 & 2 & 3 & 4 \\ 1 & 2 & 3 & 4 \\ 1 & 2 & 3 & 4 \\ 1 & 2 & 3 & 4 \\ 1 & 2 & 3 & 4 \\ 1 & 2 & 3 & 4 \\ 1 & 2 & 3 & 4 \\ 1 & 2 & 3 & 4 \\ 1 & 2 & 3 & 4 \\ 1 & 2 & 3 & 4 \\ 1 & 2 & 3 & 4 \\ 1 & 2 & 3 & 4 \\ 1 & 2 & 3 & 4 \\ 1 & 2 & 3 & 4 \\ 1 & 2 & 3 & 4 \\ 1 & 2 & 3 & 4 \\ & & & \\ 1 & 2 & 3 & 4 \\ 1 & 2 & 3 & 4 \\ 1 & 2 & 3 & 4 \\ 1 & 2 & 3 & 4 \\ 1 & 2 & 3 & 4\end{array}$

